\title{
Analysis of the Functional Space Area Configuration of a Large General Hospital in the Preliminary Planning Stage
}

\author{
Jiali YAO ${ }^{\text {a, } 1}$, Jiachen ZHONG ${ }^{\text {a }}$, Xiaoying LIU ${ }^{\text {a }}$ and Li HUANG ${ }^{\text {a,b }}$ \\ ${ }^{a}$ Zhejiang Wuzhou Engineering Project Management Co., Ltd, Hangzhou, 310051, \\ China \\ ${ }^{\mathrm{b}}$ Zhejiang University of Finance \& Economics, Hangzhou, 310018, China
}

\begin{abstract}
The area configuration of different functional spaces has an important impact on the preliminary planning of large general hospitals. This paper takes a 2000-bed hospital in Zhejiang Province as an example to introduce the area configuration of hospital's functional space in detail, including the main functional rooms on the ground and the underground buildings, and the area configuration is analyzed. The results show that the average construction area of hospital beds is 191 square meters, and the total area of buildings for seven facilities, underground garage, medical research rooms and rooms for medical equipment accounts for $92.4 \%$. In the decision-making stage of hospital construction, the area configuration of these four functional spaces should be focused to meet the needs of the hospital's operation and development.
\end{abstract}

Keywords. Preliminary planning, large general hospital, functional space, configuration analysis

\section{Introduction}

With the rapid development of social livelihood, the people have put forward higher requirements for medical infrastructure. Hospitals are an important part of the social security system for people's livelihood. The area configuration of different functional spaces in the preliminary planning stage has an important impact on the operation of the later hospital projects [1-3].

Luo Hao used linear regression to analyze the relationship between the number of beds and the total building area for general hospitals with 1100-1500 beds, and gave a linear regression equation [4]. Zhu Kun summarized and pointed out the current development situation of China's modern hospitals and the development law of the scale ratio of functional areas through on-site investigation, questionnaire and hospital interview of nine modern general hospitals in the East, middle and west regions with different economic development levels [5]. Fu Xingzhi and others pointed out how to adjust the construction standards of general hospitals to meet different development needs in combination with Longgang District Hospital project in Shenzhen [6].

\footnotetext{
1 Jiali Yao, Zhejiang Wuzhou Engineering Project Management Co., Ltd, Hangzhou, 310051, China; Email: 916207496@qq.com.
} 
However, there are relatively few studies on the functional space configuration of large general hospitals, especially for hospitals with more than 1500 beds. In this regard, this paper takes a grade III level A hospital in Zhejiang Province with 2000 beds as an example, through the research and analysis of the area configuration of different functional spaces in large general hospitals, and gives the relevant suggestions in the preliminary planning stage of the project.

\section{General Situation of Hospital}

As the first public hospital in China to pass the JCI certification, a grade III level A hospital in Zhejiang Province, integrates medical treatment, teaching and scientific research, and is a model of high-quality medical care. In response to the requirements of "double sinking and double upgrading" put forward by The People's Government of Zhejiang Province and the CPC Zhejiang Province Committee, to encourage grassroots cooperation to run hospitals under the provincial high-quality medical system, and quickly improve the medical service ability and level of district and county-level hospitals. The proposed site of the project is located in Shangyu economic and Technological Development Zone, the core area of Dawan District, Hangzhou Bay, north of Wuxing West Road and west of Hangzhou Ningbo Canal. The planned land area is $250 \mathrm{mu}$ (the Chinese version of acre), and the hospital has 2000 beds. After completion, it will provide a high-end medical treatment platform for Dawan District of Hangzhou Bay, and provide high-quality medical services and health protection for the economic construction and development of Dawan district.

\section{Hospital Staff Configuration}

The project plans to set up 2000 beds, which is a grade III level A hospital. According to the relevant provisions of the general hospital construction standard (Jianbiao 1102021), the general hospital construction standard (2018 draft), the detailed rules for the implementation of the evaluation standard for general hospitals and the trial draft of general hospital organization principles, the ratio of the number of beds to the number of staff is $1: 1.7$, so the number of staff in the hospital is 3400 , including 2448 health technicians and 952 administrative and logistics staff.

\section{Hospital Functional Space Area Configuration}

\subsection{Area configuration of Main Functional Rooms Above the Ground}

According to the general hospital construction standard and the actual situation of the project, the main function rooms include seven facilities rooms, prevention and health care rooms, medical research rooms, teaching and training rooms, library, indoor activities rooms, hospital life support rooms, large-scale medical equipment rooms, health examination center and comprehensive service center. 


\subsubsection{Seven Facilities Rooms.}

According to the general hospital construction standard, the bed average building area index of seven facilities in the general hospital, including emergency department, outpatient department, inpatient department, medical technology department, support system, administrative management and in-hospital living room, should meet the requirements of table 1 . The construction area of the seven facilities and various types of houses is shown in table 2 .

Table 1. General hospital building area index.

\begin{tabular}{lllllll}
\hline Number of beds & below 200 & $200-399$ & $400-599$ & $600-899$ & $900-1199$ & over 1200 \\
\hline Building area $\left(\mathrm{m}^{2} / \mathrm{bed}\right)$ & 110 & 110 & 115 & 114 & 113 & 112 \\
\hline
\end{tabular}

The project plans to set up 2000 hospital beds, and the building scale is calculated based on the average building area of the bed at 112 square meters. So the construction area of the seven facilities is 224000 square meters.

Table 2. Building area of seven facilities.

\begin{tabular}{llll}
\hline Department & $\mathrm{Area} / \mathrm{m}^{2}$ & Proportion & Standard \\
\hline Emergency department & 9856 & $4.40 \%$ & $3 \sim 6 \%$ \\
Outpatient department & 26880 & $12.00 \%$ & $12-15 \%$ \\
Inpatient department & 93184 & $41.60 \%$ & $37 \sim 41 \%$ \\
Medical technology & 56000 & $25.00 \%$ & $25 \sim 27 \%$ \\
department & 18144 & $8.10 \%$ & $8 \sim 12 \%$ \\
Support system & 7616 & $3.40 \%$ & $3 \sim 4 \%$ \\
Administrative management & 12320 & $5.50 \%$ & $3-5 \%$ \\
room & 224000 & $100.00 \%$ & $100 \%$ \\
In-hospital living room & & & \\
Total & & & \\
\hline
\end{tabular}

\subsubsection{Prevention and Health Care Room}

According to the construction standard of general hospital, the construction area of prevention and health care room in general hospital should be increased according to the standard of 35 square meters for each prevention and health care staff. The number of prevention and health care staff in a grade III level A hospital in Zhejiang Province is 25 , and the area of prevention and health care room in the hospital is 875 square meters.

\subsubsection{Medical Research Room}

According to the construction standard of general hospital, the general hospitals undertaking medical scientific research tasks should use $70 \%$ of the total number of professional and technical personnel at the sub-high level and above as the base, and add additional scientific research rooms at the standard of 50 square meters per person. General hospitals that carry out animal experimental research should build animal laboratories of appropriate scale according to relevant regulations. There are 612 professional technicians above the sub-high level in the hospital. According to the standard, the area of relevant scientific research room is 21400 square meters, and the area of animal laboratory is 800 square meters, for a total of 22200 square meters. 


\subsubsection{Teaching and Training Room}

According to the construction standard of general hospital, the teaching hospital should meet the building area index of $10 \mathrm{~m}^{2}$ per student, and the practice hospital should meet the building area index of $2.5 \mathrm{~m}^{2}$ per student. According to the standard, the general hospital should increase the training room area of 1000 square meters, the teaching room area of 10 square meters per person, and the dormitory area of 12 square meters per person. The project undertakes 300 teaching tasks and 150 interns every year. The teaching room area is 3375 square meters. It is planned to set up two training classrooms with 80 people in each training period. Therefore, the construction area of the training room is 3760 square meters. Therefore, the teaching and training room area of this project is 7135 square meters.

\subsubsection{Other Rooms}

Other rooms include library, indoor activity room, hospital life support room, health examination center and comprehensive service center. The general hospital construction standard increases the area of general hospital library, indoor activity room and hospital life support room. Among them, the library increases the building area according to the standard of $2 \mathrm{~m}^{2}$ per person, the indoor activity room increases the building area according to the standard of $1 \mathrm{~m}^{2}$ per person, and the hospital life support room increases the building area according to the standard of $0.4 \mathrm{~m}^{2}$ per bed.

The library area of this project is 2040 square meters, the indoor activity room area is 2020 square meters, the hospital life support room area is 800 square meters, and the health examination center area is 5000 square meters, and the comprehensive service center area is 3650 square meters. The total other area is 13510 square meters.

\subsubsection{Large-scale Medical Equipment Room}

According to the construction standard of general hospital, the area of large-scale medical equipment room needs to be calculated separately. According to the actual demand, the area of large-scale medical equipment room is 13280 square meters, all kinds of rooms are shown in table 3.

Table 3. Area of large-scale medical equipment room.

\begin{tabular}{llll}
\hline Equipment & Number & Single area $/ \mathrm{m}^{2}$ & Total area $/ \mathrm{m}^{2}$ \\
\hline X-ray computed tomography & 10 & 260 & 2600 \\
magnetic resonance imaging system & 6 & 310 & 1860 \\
X-ray machine & 12 & 320 & 3840 \\
gastrointestinal machine & 2 & 200 & 400 \\
linear accelerator & 4 & 470 & 1880 \\
radio wave knife & 1 & 450 & 450 \\
tomo therapy & 1 & 450 & 450 \\
CT simulation system & 1 & 600 & 600 \\
MR simulation system & 1 & 300 & 300 \\
PET-CT & 1 & 300 & 300 \\
PET-MR & 1 & 600 & 600 \\
total & & & 13280 \\
\hline
\end{tabular}




\subsection{Area Configuration of Underground Buildings}

According to the construction standard of general hospital, parking facilities for motor vehicles and non motor vehicles should be built in new general hospitals. The number of parking and the area index of parking facilities should be implemented according to the relevant regulations of the area where the construction project is located.

The demand for motor vehicle parking numbers in this project is 2542 , and nonmotor vehicle parking numbers is 6273 . The project adopts a parking method that combines ground and underground. It is planned that $90 \%$ of the number of motor vehicles and non-motor vehicles will be parked underground. The construction area of underground parking garage is $36 \mathrm{~m}^{2}$ per standard parking space and the non-motor vehicle parking garage is $1.8 \mathrm{~m}^{2}$ per standard parking space. The area of the underground parking garage is 92531 square meters. Considering the needs of civil defense rooms and equipment rooms, the underground building area is determined to be 100000 square meters.

\subsection{Analysis of Functional Space Configuration of Hospital Buildings}

A grade III level A hospital in Zhejiang Province plans to set up 2000 beds, with a total construction area of 381000 square meters, and an average building area of 190.5 square meters. The above ground building area is 281000 square meters, accounting for $73.8 \%$ of the total building area. The underground construction area is 100000 square meters, accounting for $26.2 \%$ of the total building area. The main room area is shown in figure 1.

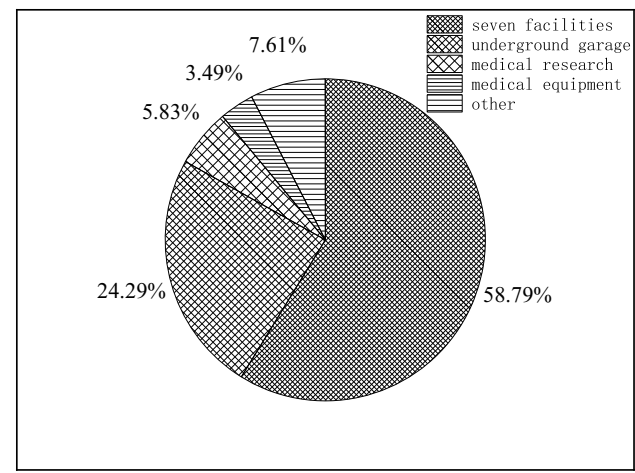

Figure 1. Main room area.

The above ground buildings include seven facilities rooms, prevention and health care rooms, medical research rooms, teaching and training rooms, library, indoor activities rooms, hospital life support rooms, large-scale medical equipment rooms, health examination center and comprehensive service center. The underground buildings include parking garage, civil defense rooms and equipment rooms.

According to the analysis in figure 1, the area of seven facilities is 224000 square meters, accounting for $58.8 \%$ of the total construction area. The underground garage area is 92531 square meters, accounting for $24.3 \%$ of the total construction area. The area of medical research room is 22200 square meters, accounting for $5.8 \%$ of the total 
construction area. The area of medical equipment room is 13280 square meters, accounting for $3.5 \%$ of the total construction area. The area of other buildings is 28989 square meters, accounting for $7.6 \%$ of the total construction area.

\section{Conclusion}

This paper takes a grade III level A hospital in Zhejiang Province with a planned number of 2,000 beds as an example, and analyzes the construction area configuration of a large general hospital in the preliminary planning stage. The conclusions are as follows.

(1) In the area configuration of the functional space of a large general hospital, the total area of buildings for seven facilities, underground garage, medical research rooms and rooms for individual projects accounts for as much as $92.4 \%$. Among them, the area of buildings used for seven facilities accounts for $58.8 \%$, the area of underground garage accounts for $24.3 \%$, the area of medical research buildings accounts for $5.8 \%$, and the area of buildings used for separate projects accounts for 3.5\%. In the feasibility study stage of hospital construction, the area configuration of the above-mentioned four functional spaces should be focused on.

(2) For a grade III level A hospital with a planned number of 2,000 beds, the average construction area of hospital beds is as high as 191 square meters. The reason is that when the number of beds reaches a certain scale, the hospital building space design becomes more and more high-quality, and the total building area increases accordingly.

\section{References}

[1] Larsen A, Karlsen A, Andersen B. Hospital project front-end planning: Current practice and discovered challenge. Project Leadership and Society. 2020 Dec; 12(1): 1-14.

[2] Risse GB. Humanizing hospital space: A revolution in health care design. Proceeding of Form and Function: The Hospital-International Network for the History of Hospitals; 2003 June 19-21; Montreal. p. 1-26.

[3] Biddiss E, Mcpherson A, Shea G, et al. The design and testing of interactive hospital spaces to meet the needs of waiting children. Herd. 2013 Apr; 6(3): 49-68.

[4] Luo H. Large-scale general hospital medical area index of function space. Beijing: Beijing University of Civil Engineering and Architecture; 2016. p. 38-46.

[5] Zhu K. The Study on scale ratio of functional divisions of the modern third-grade class-A general hospital. Guangzhou: South China University of Technology; 2013. p. 47-69.

[6] Fu XZ, Yang M, Zheng J. Study on urban hospital planning construction index regulation. Shanxi Architecture. 2010 Feb; 36(18): 13-14. 